\title{
Reduced Ecological Footprints of Modern Facilities Introducing the Implementation of Advanced Wireless Technologies, and Human Resources' Benefits
}

\author{
Spyridon K. Chronopoulos ${ }^{1,2,3}$, Evangelia I. Kosma ${ }^{4,5}$, Dionysios Tafiadis ${ }^{6}$, Dimitrios Dimopoulos ${ }^{3}$, \\ Vasilis Raptis ${ }^{1,3}$, Evaggelos C. Karvounis', Pantelis Angelidis' ${ }^{2}$, Panos Kostarakis ${ }^{1}$ \\ ${ }^{1}$ Physics Department, Electronics-Telecommunications and Applications Laboratory, University of Ioannina, Ioannina, Greece \\ ${ }^{2}$ Department of Informatics and Telecommunications Engineering, University of Western Macedonia, Kozani, Greece \\ ${ }^{3}$ Department of Computer Engineering, Technological Educational Institute of Epirus, Epirus, Greece \\ ${ }^{4}$ Faculty of Medicine, School of Health Sciences, University of Thessaly, Larissa, Greece \\ ${ }^{5}$ Mihail Aggelou 18, Ioannina, Greece \\ ${ }^{6}$ Department of Speech \& Language Therapy, Technological Educational Institute of Epirus, Ioannina, Greece

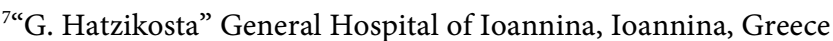 \\ Email: schrono@cc.uoi.gr, schronopoulos@uowm.gr, spychro@teiep.gr, ekosma@med.uth.gr, evikosma@gmail.com, \\ paggelidis@uowm.gr, kostarakis@uoi.gr
}

How to cite this paper: Chronopoulos, S.K., Kosma, E.I., Tafiadis, D., Dimopoulos, D., Raptis, V., Karvounis, E.C., Angelidis, P. and Kostarakis, P. (2018) Reduced Ecological Footprints of Modern Facilities Introducing the Implementation of Advanced Wireless Technologies, and Human Resources' Benefits. Communications and Network, 10, 11-29. https://doi.org/10.4236/cn.2018.101002

Received: November 19, 2017

Accepted: December 15, 2017

Published: December 18, 2017

Copyright (c) 2018 by authors and Scientific Research Publishing Inc. This work is licensed under the Creative Commons Attribution International License (CC BY 4.0).

http://creativecommons.org/licenses/by/4.0/ cc) (i)

Open Access

\begin{abstract}
The necessity of lowering the mean power consumption of various facilities, due to the lack of their enormous future energy needs, led to an ongoing advance of various technologies. These technologies have been oriented towards the concept of a Reduced Ecological Footprint. Massive structures (such as building complexes and hospitals) have been redesigned and upgraded; many interior designs have been dramatically altered while new electronic devices are constantly being produced in order to revolutionize a long term perspective towards a "Green Planet" while they exhibit astonishing signal processing. Consequently, an enormous technology already exists which needs to be properly combined to a proposed methodology and to new ideas relevant to systems' administration through automatic wireless control. This paper intends to reduce the gap between design and realization of the aforementioned research. Consequently, the primary contribution of this research is the proposal of a complete design protocol with minimized defects relevant to Reduced Ecological Footprints of Facilities (REFF) along with its beneficial advantages relevant to providing a healthy and productive work environment. This protocol consists of four main parts which are 1) the main key points-guidelines, 2) its objectives, 3) the know-how methodology for implementation in existing installa-
\end{abstract}


tions and 4) the description of the imminent benefits in workforce/human resources.

\section{Keywords}

Reduced Ecological Footprint, Energy Needs, Wireless Communications, Sensors, Workforce Productivity

\section{Introduction}

Facilities such as housings, university edifices, hospitals and generally large building complexes, have enormous energy needs compared to the past. The imminent effects, at various locations around the world, are the climate changes that are provoked by large gasses emission leading to greenhouse effect. As energy needs are constantly arising (with the consequent necessity of upgrading or building new power facilities contributing to new considerable gasses emissions), it is too hard at the same time to merely expand power plants and to add more generator units because the conclusion would be the production of undesirable emissions (e.g. $\mathrm{CO}_{2}$ ). Other facilities of producing energy such as nuclear power plants (apart from requiring very strict safety measures against radiation containment) introduce the danger of irreversibly polluting the environment. Consequently, reduced energy consumption schemes would help towards decreased power consumption [1] [2].

Notably, the upgrade of aforementioned structures with low energy consumption electronics and telecommunications [3] and low-energy heating and cooling installations will still not be a holistic approach towards converting the building to a small and "autonomous green power plant". The last condition will need a significant structure's upgrade not only by containing new photovoltaic sources but moreover through the implementation of new techniques for redesigning and accomplishing a sustainable environment of advanced living conditions applied to all the nearby building community and not only for partial-individual purposes. Especially in the past, the previous strategy was not followed in the proper proportion concluding to a rather chaotic result by living districts or isolated structures with no natural connectivity to the rest [4]. If we combine the previous significant knowledge with the fact of a non-holistic approach in the case of a reduced footprint applied only to a limited number of buildings of a complex, then this situation could lead definitely to a significant problem. This problem could act as a large gap comparing the "different types of buildings" along with their residents' philosophy of creating and sustaining a "clean" environment against their neighbors' houses lack of ecological upgrade hence with their reluctance of adopting the ecological way of living [5]. This situation could definitely lead to a lack of natural connectivity between various populations and obviously not to the best possible result relevant to reduced ecological footprint. 
Furthermore, along with the previous energy needs, an extensive introduction of wireless technology [6] [7] [8] [9] has been implemented with various forms such as smart devices with network capabilities [10] [11] [12]. If these devices conform to the specifications of management systems like HEMS [13] then it is possible the real-time monitoring through interface systems. The aforementioned management systems can adapt to various power and environmental conditions while at the same time would take into consideration the different electricity prices in a day's time. These systems could implement the supervision of advanced metering infrastructure (AMI), advanced sensor applications, bidirectional communications and energy storage systems (e.g. HESS-home energy storage system). Especially, the AMI devices have the capability of sustaining a bidirectional communication between the users and the various utilities. Consequently, this can lead to energy saving through automated techniques and especially remote energy management with the help of smart devices under a smart communication grid [14] [15]. Moreover, if the facilities are equipped with the technology of Internet of Things (IoT), then the energy saving can be even greater since all the physical objects such as e.g. lighting, heating units, detectors, etc. can send and receive data for desired and predefined operating modes [16]. It must also be noted the fact that power grid should be optimized against high peak-to-average ratio with the use of well-known and successful signal processing techniques [17] [18].

The design protocol of Reduced Ecological Footprints of Facilities (REFF) has the primary goal to propose already known advanced materials and technology [19] [20] [21] [22] for reforming existing buildings in order to consume less energy and at the same time to present the maximum functionality in all areas (e.g. sophisticated motion detectors and automated processes of making decisions). Specifically, as mentioned above, already known technology could be implemented such as system regulators, control of microclimate conditions etc. In this occasion, advanced thermostats could be used with high efficiency decision making mechanisms [23]. Their functional characteristics include automatic retrieval of weather forecasts (every hour) with a range of five days in advance. Consequently, home temperature could be optimized automatically and in real-time-mode based on resident's needs and on sudden drop or increase in temperature. Furthermore, the characteristic of individual sensors inside each room (with occupational detection) in order to optimize the room against undesirable hot or cold spots could enhance even more residential conditions and at the same time to contribute in power saving of about $20 \%-30 \%$ each year. Additional feature of such thermostats include the knowledge of external temperature and sun position even relevant to sensor (for excluding misreading due to incidence of sun rays). Wireless technologies are also part of the informative grid through the use of wireless phones which through the transmission of their owners' position coordinates could enhance even more the decrease in power consumption. This is accomplished as the thermostats know the exact position of the facility's occupants and they accordingly adjust the temperature by even foreseeing the average time of coming back to the residence. Examples of commercial thermostats' photos are presented in 
Figure 1 [24] [25] [26] [27] [28].

Moreover, buildings' supervision should be automated to the greatest possible extent, in order these smart buildings to serve most of the needs of their residents or workers, without sacrificing the functionality of their spaces due to the large reduction of power consumption.

This paper is split into six sections. The next section presents the key protocol points (code numbered) of REFF, the third section foresees the objectives and benefits of applying the REFF, while the fourth section mentions the typical methodology that should be followed in order the proposed protocol to be implemented in facilities and where applicable. In the fifth section, the beneficial results are presented upon workers or people through the application of such green technological update in existing facilities or living quarters apart from new buildings or edifices. In conclusion (sixth section) the main points of the proposed protocol are shown along with future potential propositions under consideration.

\section{Key Protocol Points of Reduced Ecological Footprints of Facilities}

The main key protocol points (PP) of the proposed protocol of Reduced Ecological Footprints of Facilities (REFF) are shown in Figure 2 and are analyzed below:
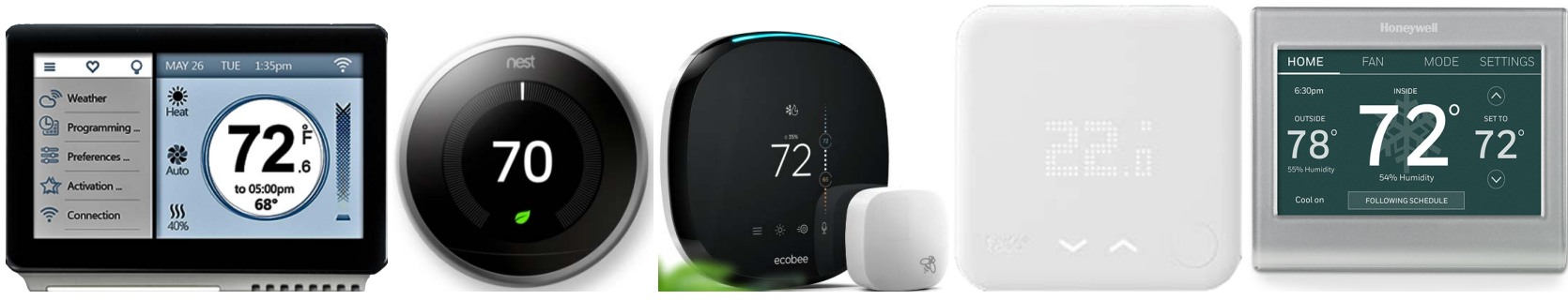

Figure 1. Photos of various smart commercial thermostats [24] [25] [26] [27] [28].

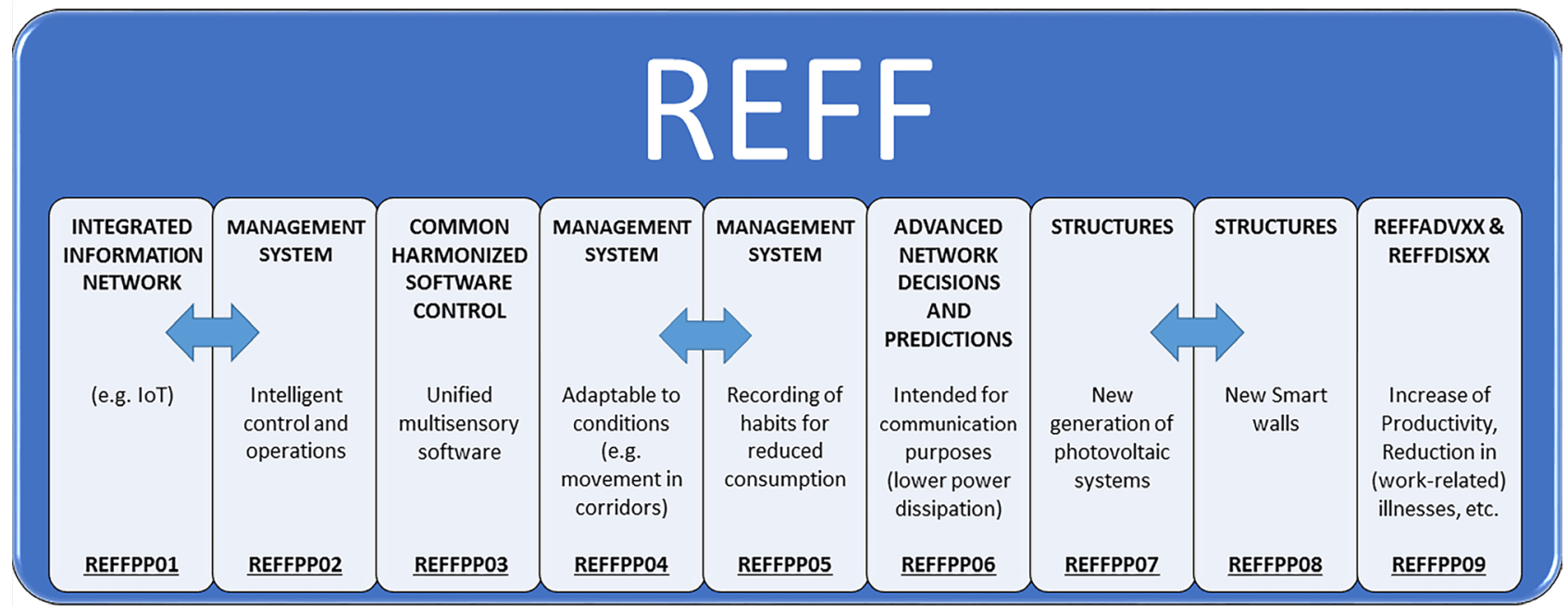

Figure 2. Schematic diagram of the main points of the proposed protocol. 
- (REFFPP01): The candidate facilities should include IoT [29] technology as part of an integrated information network (Figure 3) through which various components such as sensors, decision making systems and subsystems' operation control will be interconnected [30] [31].

- (REFFPP02): Intelligent control and operational systems of lighting, of microclimate conditions, of heating and cooling [24] [25] [26] [27] [28], and other functions should be installed along with the implementation of various measuring devices inside and outside buildings (e.g. measuring environmental conditions and light intensity, motion detectors, etc., Figure 4). The intelligent management system will adapt itself to the proper energy requirements due to the prior knowledge of the external and internal building's conditions [32] [33].

- (REFFPP03): The multiple sensors which will be integrated in order to constantly monitor and give feedback to the control platform should be based on

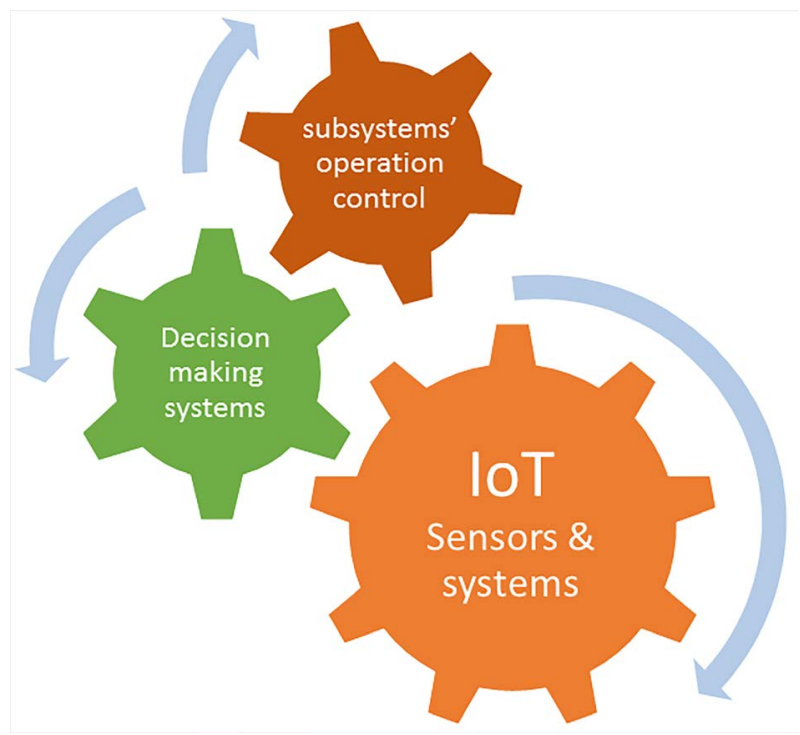

Figure 3. Relationship of inter-association between various subsystems of REFFPP01.

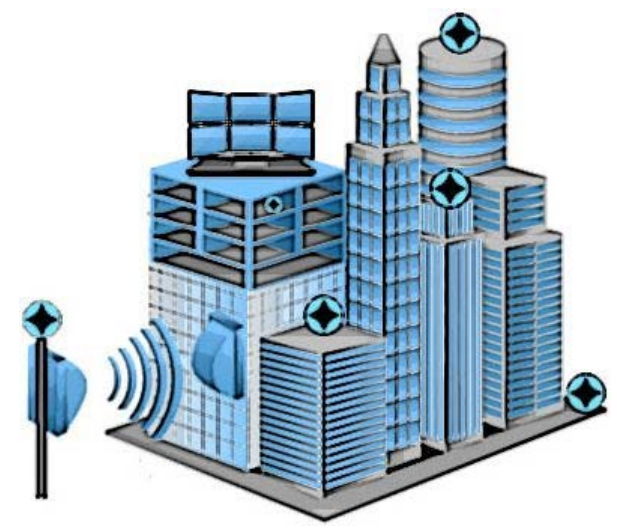

Figure 4. REFFPP02-example of schematic diagram of measuring devices (circular objects) inside and outside buildings (this figure was partially created using Smart Draw 2017 Trial Edition) [52]. 
a well-adjusted Common Harmonized Software Control (CHSC). This universal approach towards creating a unified multisensory software, which will e.g. call a function on every sensor at the same address, will greatly simplify the whole procedure of implementation. Subsequently this approach will help towards avoiding confusions and conflicts in software and in hardware level. An example of sensors unified approach is reported in [34].

- (REFFPP04): Increased energy efficiency with the help of an advanced management system. This system, apart from making typical decisions, will have the ability to adapt depending on the circumstances (e.g. rare or reduced movement of people in corridors where the lighting will be mostly low even in theoretical "peak working hours") [35] [36].

- (REFFPP05): The habits of employees or residents will be recorded (without violating personal data and respecting GDPR [37]) by the electronic web management system at each individual workplace in order to be conducted immediate optimization of energy consumption [38] [39] [40]. Also, there will be the possibility of reduced and personalized energy consumption depending on the preferences of each employee in his/her private workplace, and provided that the consumption will not exceed predetermined maximum power levels [39] [40].

- (REFFPP06): Advanced network decisions and predictions [41], control algorithms and concatenated coding (for communication purposes with a typical of 20\% lower power dissipation) [42] [43] [44] should be used for the optimal management of energy systems producing the lowest possible carbon footprint [45].

- (REFFPP07): New generation of photovoltaic systems should be included in the overall implementation for the most productive conversion of solar to electrical energy (depending on the amount of funding). Moreover a smart information grid (e.g. such as in [46] for hospitals) should be deployed which will use machine learning combined with sensors and algorithms as parts of the proposed "Smart Decisions for Energy Efficiency" (Figure 5) [47] [48] [49] [50].

- (REFFPP08): Smart walls will heat the interior microenvironment while saving large amounts of energy because they can use green power sources such as solar energy [51].

- (REFFPP09): This protocol complies with the advantages-REFFADVXX and it copes with the disadvantages-REFFDISXX which are discussed under Section 5.

\section{Objectives and Benefits of REFF Protocol}

The REFF protocol in short and long term will yield benefits relevant to energy saving with practical ways of thinking (easy installation, smart and adaptable systems) which will hence include the alteration of existing residential facilities, organizations, hospitals, schools etc. [53] [54] [55] and at the same time the following 


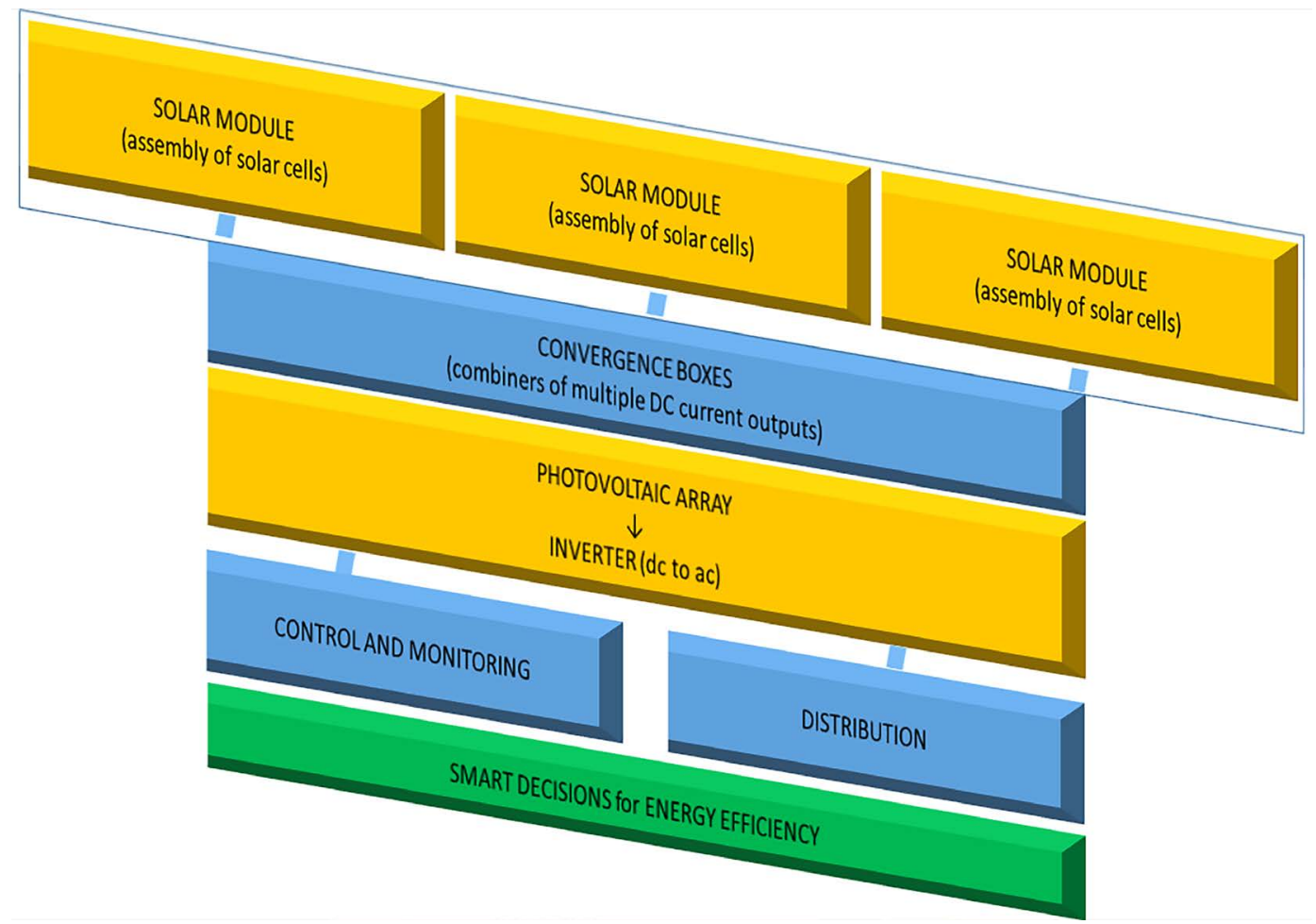

Figure 5. Schematic diagram of a new generation photovoltaic system.

objectives (OBJ) should be obtained:

- (REFFOBJ01): Development of methodology and creation of a customized and easily adaptable communication network. This network will be a bridge between all the smart micro-sensors and intelligent system's functions which will be also updatable via software techniques [56].

- (REFFOBJ02): Upgrade of the existing communication and power network with innovative energy-efficient technologies such as in [57].

- (REFFOBJ03): Software which will include the overall systems' control along with a database in which will be recorded each operation and prediction in order all the saved data to be used for future study and possible improvement of REFF's operation.

- (REFFOBJ04): The development of new control algorithms [58] [59] not only for low power consumption but also for the creation of a microclimate which will lead to employees' productivity increase.

- (REFFOBJ05): Advanced function of data dissemination which will include notification to mobile devices using existing and popular communication software.

- (REFFOBJ06): Online information (using Internet) with the use of intelligent algorithms presenting the load state of the power network and each of the employee's efficiency. These algorithms, along with the low energy consumption monitoring of each area and of every worker's habits, will assist in predicting and in advancing productivity levels.

- (REFFOBJ07): Creation of buildings and system models with reduced energy 
footprint for the purpose of being used for further systems' betterment (depending on the amount of funding).

\section{Work Packages for Implementing the REFF Protocol}

The REFF protocol should include in any case the following work packages (WP) which will be part of the heart of integrated Reduced Ecological Footprint Facility technology in new or existing installations:

- (REFFWP01): Original system design and energy saving prediction, with the creation of advanced software (if necessary), being easily customizable to the specific type of facility [60].

- (REFFWP02): Construction of a communication network or upgrading an existing one that can support as many as possible remote sensors and intelligence systems for microclimate, external climate etc [61].

- (REFFWP04): The implementation of sensors should comply with Common Harmonized Software Control (CHSC) which is reported in REFFPP03.

- (REFFWP05): Installation of low energy consumption electronic systems (including sensors).

- (REFFWP06): Modification of facility's mechanical or building parts (depending on the building type and the amount of funding) [62] [63] [64].

- (REFFWP07): Installation of alternative heating and power sources [65] [66] [67].

- (REFFWP08): Creation of a central system for controlling, collecting and processing information.

- (REFFWP09): Implementation of an information infrastructure for the uninterrupted system operation.

- (REFFWP10): Development or use of intelligent algorithms of energy control and other operations with the primary focus on their future optimization [68] [69].

- (REFFWP11): Verification of the final system's version proper operation (in all levels of implementation) for the purpose of optimization.

- (REFFWP12): Dissemination of every study and result, aiming to promoting science in the investigated field of development.

\section{Beneficial Results of REFF Protocol on Workers and Residents}

So far, the conventional buildings are correlated to the high incidence of negative effects in their residents' health from factors due to Indoor Environmental Quality (IEQ) which are the Sick Building Syndrome (SBS), the Multiple Chemical Sensitivity (MCS) and the Building Related Illness (BRI). Therefore, in the context of implementing green power solutions, the research is constantly increasing on topics such as the impact of the energy buildings (or else known as Leadership in Energy and Environmental Design-LEED buildings) conditions' on health, work satisfaction and employees (residents) productivity [70]. 
The typical internal environmental design criteria for the creation of healthy, comfortable and productive indoor environments include various factors. These are the indoor air quality, the low emission materials and devices, the proper containment of indoor pollutants or chemicals in non-detectable levels, the ability of advanced control systems, the thermal comfort and lighting, high-quality view, ergonomics, acoustics and aesthetics [71].

Poor indoor environmental quality has been proven to be related to the appearance of various health issues and problems on employees. The undesired characteristics such as poor air quality, extreme temperature, excessive humidity and insufficient ventilation may adversely affect the health of the residents/employees by causing or exacerbating diseases such as asthma and respiratory allergies. In addition to physical health, the psychological health can be affected due to inadequate illumination, problematic acoustics, non-functional and non-ergonomic design. These kind of building features may cause various disorders' (such as depression, stress, voice disorders) onset or worsening [72] [73] [74] [75] [76].

The aforementioned problems are in turn associated to the decreased workers' productivity and work satisfaction inside such buildings. It has been found that employees which suffer from the above physical and psychological health problems are more likely to be absent more frequently from their work (while exhibiting lower levels of productivity and satisfaction from environmental working conditions) than typical healthy workers [77] [78].

The study of the energy buildings' usefulness has exhibited significant benefits. These benefits are associated to saving economic resources through productivity increase with decreased safety and health costs, and through reduced operating costs, maintenance and energy consumption [79] [80]. However, the studies so far, which are aimed to empirically support the key-points on which the energy buildings (health, satisfaction, and productivity) outperform conventional buildings, present conflicting results. According to a survey at 25 energy buildings in Illinois (US), it has been found that only in 2 buildings was observed decreased asthma, less absence and sickness time, increased awareness of the main activity and increased recruitment (staff). The workers mentioned as beneficial factors (of energy buildings) the indoor air quality and lighting which contributed to increased satisfaction. The complaint, which was expressed by their majority, concerned the lack of temperature control in their workplace, condition that increased their physical discomfort [81]. According to other surveys, the users of energy buildings see positively the use of natural lighting, the existence of external view and generally the bond with nature, the good ventilation and the pleasant space aesthetics [82] [83]. Another study which was related to an energy building in Maryland (US), concluded throughout the whole procedure of research, to positive results. Research findings can be summarized as follows: High satisfaction for building installations, from indoor air quality, from natural lighting and access to the outside environment, high psychosocial satisfaction (high levels of morality, euphoria and sensation of being part of the staff) and a high sense of pride for 
the building where employees work. The only disadvantage, which was spotted from the building's users, was the problems due to the inappropriate acoustic conditions (distractions by talking and the lack of private talks) due to the existence of an open internal environment (absence of doors and isolated office spaces). The most frequently mentioned concerns were the temperature conditions, distractions from noise and the glare through the windows [84].

The energy buildings which include interiors of high-visibility (stairs in open space, low barriers, crowding, and central traffic systems) can affect users both in a positive (ease of interaction and communication) and in a negative way (increased distractions). In particular, the positive effects are related to increased awareness and communication while they increase productivity and the on time problem solving [85] [86]. The negative effects of open indoor spaces are reported by acoustic complaints and related to loss of privacy. This condition results to responding difficulties when various complex cognitive tasks (writing, reading, analysis) are conducted. In turn, this contributes to working pauses and to the reduction in individual productivity [87] [88].

Another study in 15 energy buildings in the United States has shown that the quality of office furnishings (comfort, flexibility and aesthetics) had a significant impact on employees' satisfaction and performance, while indoor air quality affected only productivity. Specifically, users' satisfaction was high in contrast with acoustic quality and with proper temperature control, while productivity was only negatively related to acoustic quality. Especially the cabin workers exhibited satisfaction and productivity independent of the audio conditions (telephone communication and discussion in close proximity between colleagues, private communication). In regard to proper temperature control which is associated to physical discomfort, there were complaints about the lack of accessing the thermostat (as aforementioned in another research) and the different temperature between the interiors [89]. Moreover, several studies have concluded to the fact that environmental working conditions (indoor air quality) have a positive correlation to productivity, physical and psychological euphoria and cognitive function, and a negative correlation to morbidity and mortality [90]-[95]. In accordance to the aforementioned research, an additional research suggests that the improved indoor environment of the energy buildings contributes to the betterment of health and productivity of its users, as it is reported a reduction in absences and a reduction in (work-related) illnesses such as asthma, respiratory allergies, depression and anxiety [96]. However, researches have been conducted relevant to the existence of ergonomic design in energy buildings. These researches have highlighted the need for a thorough study of indoor ergonomics as its lack is associated with the appearance of musculoskeletal problems [97] [98].

The advantages (REFFADVXX) and disadvantages (REFFDISXX) that could be emerged when working inside a LEED building are summarized below. These advantages are directly associated to the proposed REEF Protocol which is taking into consideration the disadvantages for eliminating some emerged unplea- 
sant conditions:

- (REFFADV01): Productivity increase.

- (REFFADV02): Increased Satisfaction (due to e.g. indoor air quality and lighting).

- (REFFADV03): Increased awareness of the main activity.

- (REFFADV04): Increased recruitment of staff.

- (REFFADV05): High psychosocial satisfaction (e.g. euphoria and sensation of being part of the staff).

- (REFFADV06): High sense of pride for the building where employees work.

- (REFFADV07): Reduction in (work-related) illnesses such as asthma, respiratory allergies, depression and anxiety.

- (REFFDIS01): Lack of temperature control in the workplace increases the physical discomfort. Therefore, it is proposed the personal-space temperature control with \pm 2 deviation degrees in Celsius scale, in order not to be greatly affected the temperature of adjacent offices.

- (REFFDIS02): Inappropriate acoustic conditions can lead to discomfort and consequently to pause of services and faulty communication procedures. It is recommended the staff to use mobile electronic devices such as Bluetooth headphones/microphone in order to communicate in the presence of severe noise. Also, ergonomic design must be taken into consideration in relevance to the proper construction of corridors especially from soundproof materials, in order to be prevented the reflection of unwanted audio waves.

- (REFFDIS03): Glare from windows could distract a worker, leading him/her to reduction of productivity and imminent illness such as headaches. It is recommended the windows to be carefully designed in order to reflect the light in places where the diffusion could be conducted free of glare effects or the light could be absorbed (e.g. Black material such as Vantablack) [99].

- (REFFDIS04): Indoor ergonomics should be improved as their lack of proper design is related to musculoskeletal problems.

\section{Conclusions and Future Scopes}

This paper discusses the main points for constructing or modifying buildings based on the specifications of green structures (such as Philip Merrill Environmental Center building in Anapolis, Maryland, US [84], fifteen LEED-certified office buildings [89] and two buildings located at the University of Alberta, Edmonton, Canada [98]) with reduced ecological footprints. These structures are also compliant with the term "energy buildings" and the term "LEED buildings". The proposed protocol (Figure 2) consists of four main parts which contain the general ideas behind a methodology of accomplishing the beneficial impacts on employees/users apart from the reduced energy consumption and the green power compliance. Especially in the fourth part, small scale solutions are proposed relevant to emerging disadvantages of green buildings.

The proposed protocol is a general guide accompanied with rules but with the 
flexibility to be further enriched with emerging technologies and designs. These designs could range from new green power production to new wireless technologies along with the fact of always taking into account the element of helping humans towards living into a cleaner environment.

\section{References}

[1] Stoll, P., Brandt, N. and Nordström, L. (2014) Including Dynamic $\mathrm{CO}_{2}$ Intensity with Demand Response. Energy Policy, 65, 490-500.

https://doi.org/10.1016/j.enpol.2013.10.044

[2] Beaudin, M. and Zareipour, H. (2017) Home Energy Management Systems: A Review of Modelling and Complexity. In: Zhang, X. and Dincer, I., Eds., Energy Solutions to Combat Global Warming, Springer, Cham, 753-793. https://doi.org/10.1007/978-3-319-26950-4_35

[3] Chronopoulos, S. (2014) Study and Impact Considerations of Various Aspects in OFDM Signals. Doctoral Dissertation, University of Ioannina, School of Sciences. Department of Physics, Electronics-Telecommunications and Applications Laboratory.

[4] Corbusier, L. and Etchells, F. (2014) Towards a New Architecture. Martino Publishing, Eastford.

[5] Wang, N., Phelan, P.E., Harris, C., Langevin, J., Nelson, B. and Sawyer, K. (2018) Past Visions, Current Trends, and Future Context: A Review of Building Energy, Carbon, and Sustainability. Renewable and Sustainable Energy Reviews, 82, 976-993. https://doi.org/10.1016/j.rser.2017.04.114

[6] Chronopoulos, S.K., Christofilakis, V., Tatsis, G. and Kostarakis, P. (2016) Preliminary BER Study of a TC-OFDM System Operating under Noisy Conditions. Journal of Engineering Science and Technology Review, 9, 13-16.

[7] Chronopoulos, S.K., Christofilakis, V., Tatsis, G. and Kostarakis, P. (2016) Performance of Turbo Coded OFDM under the Presence of Various Noise Types. Wireless Personal Communications, 87, 1319-1336. https://doi.org/10.1007/s11277-015-3055-1

[8] Raptis, V., Tatsis, G., Chronopoulos, S.K., Mallios, S. and Kostarakis, P. (2013) Development and Experimental Measurements of a Tunable Antenna. Communications and Network, 5, 220-224. https://doi.org/10.4236/cn.2013.53026

[9] Koumasis, A., Chronopoulos, S.K., Angelis, C.T., Koliopanos, C., Tombros, S. and Kavadias, C. (2006) Smart Antennas with E-Shaped Patch for 3G Applications. WSEAS Transactions on Communications, 5, 1636-1641.

[10] Zhou, B., Li, W., Chan, K., Cao, Y., Kuang, Y., Liu, X. and Wang, X. (2016) Smart Home Energy Management Systems: Concept, Configurations, and Scheduling Strategies. Renewable and Sustainable Energy Reviews, 61, 30-40. https://doi.org/10.1016/j.rser.2016.03.047

[11] Angelis, C.T. and Chronopoulos, S.K. (2011) System Performance of an LTE MIMO Downlink in Various Fading Environments. In: Gabrielli, S., Elias, D. and Kahol, K., Eds., Ambient Media and Systems, AMBI-SYS 2011, Springer, Berlin, Heidelberg, 36-43. https://doi.org/10.1007/978-3-642-23902-1_5

[12] Chronopoulos, S.K., Koliopanos, C. and Angelis, C.T. (2007) Satellite Multibeam Signaling for Multimedia Services. Proceedings of the 3 rd International Conference on Mobile Multimedia Communications, Nafpaktos, 27-29 August 2007, 1-4. https://doi.org/10.4108/ICST.MOBIMEDIA2007.1693 
[13] Han, J., Choi, C.S., Park, W.K. and Lee, I. (2011) Green Home Energy Management System through Comparison of Energy Usage between the Same Kinds of Home Appliances. 2011 IEEE 15 th International Symposium on Consumer Electronics (ISCE), Singapore, 14-17 June 2011, 1-4. https://doi.org/10.1109/ISCE.2011.5973168

[14] Siano, P. (2014) Demand Response and Smart Grids-A Survey. Renewable and Sustainable Energy Reviews, 30, 461-478. https://doi.org/10.1016/j.rser.2013.10.022

[15] Erol-Kantarci, M. and Mouftah, H.T. (2015) Energy-Efficient Information and Communication Infrastructures in the Smart Grid: A Survey on Interactions and Open Issues. IEEE Communications Surveys \& Tutorials, 17, 179-197. https://doi.org/10.1109/COMST.2014.2341600

[16] Shakeri, M., Shayestegan, M., Abunima, H., Reza, S. S., Akhtaruzzaman, M., Alamoud, A. R. M., Sopian, K. and Amin, N. (2017) An Intelligent System Architecture in Home Energy Management Systems (HEMS) for Efficient Demand Response in Smart Grid. Energy and Buildings, 138, 154-164. https://doi.org/10.1016/j.enbuild.2016.12.026

[17] Chronopoulos, S.K., Tatsis, G., Raptis, V. and Kostarakis, P. (2011) Enhanced PAPR in OFDM without Deteriorating BER Performance. International Journal of Communications, Network and System Sciences, 4, 164-169. https://doi.org/10.4236/ijcns.2011.43020

[18] Chronopoulos, S.K., Christofilakis, V., Tatsis, G. and Kostarakis, P. (2012) Reducing Peak-to-Average Power Ratio of a Turbo Coded OFDM. Wireless Engineering and Technology, 3, 195-202. https://doi.org/10.4236/wet.2012.34028

[19] Chronopoulos, S.K., Votis, C., Raptis, V., Tatsis, G. and Kostarakis, P. (2010) In Depth Analysis of Noise Effects in Orthogonal Frequency Division Multiplexing Systems, Utilising a Large Number of Subcarriers. AIP Conference Proceedings, 1203, 967-972.

[20] Tatsis, G., Votis, C., Raptis, V., Christofilakis, V., Chronopoulos, S.K. and Kostarakis, P. (2010) Design and Implementation of Ultra-Wideband Impulse Radio Transmitter. AIP Conference Proceedings, 1203, 579-584. https://doi.org/10.1063/1.3322513

[21] Tatsis, G., Votis, C., Raptis, V., Christofilakis, V., Chronopoulos, S.K. and Kostarakis, P. (2010) Performance of UWB-Impulse Radio Receiver Based on Matched Filter Implementation with Imperfect Channel Estimation. AIP Conference Proceedings, 1203, 573-578.

[22] Tatsis, G., Christofilakis, V., Votis, C., Kostarakis, P., Ivrissimtzis, L. and Chronopoulos, S.K. (2011) BER Performance of an Ultra-Wideband Impulse Radio Correlator Receiver. WSEAS Transactions on Information Science and Applications, 8, 401-406. http://www.wseas.us/e-library/transactions/information/2011/54-113.pdf

[23] Danassis, P., Siozios, K., Korkas, C., Soudris, D. and Kosmatopoulos, E. (2017) A Low-Complexity Control Mechanism Targeting Smart Thermostats. Energy and Buildings, 139, 340-350. https://doi.org/10.1016/j.enbuild.2017.01.013

[24] (2017) ecobee4 | Smart WiFi Thermostats by ecobee. Ecobee.com. https://www.ecobee.com/ecobee4/

[25] (2017) Vine Smarthome Product-Vine Smarthome. xingconnected.com. https://www.xingconnected.com/main/product.do

[26] (2017) A Nest Thermostat for Every Home. Nest. https://nest.com/thermostats/

[27] (2017) Thermostats-WiFi, Smart, Digital | Honeywell. Yourhome.honeywell.com. https://yourhome.honeywell.com/en/products/thermostat 
[28] (2017) Smart Thermostat for Heating Systems and Radiators $\mid$ tado $^{\circ}$. tado $^{\circ}$. https://www.tado.com/gr/thermostat-heating

[29] Imadali, S., Karanasiou, A., Petrescu, A., Sifniadis, I., Vèque, V. and Angelidis, P. (2012) eHealth Service Support in IPv6 Vehicular Networks. IEEE 8th International Conference on Wireless and Mobile Computing, Networking and Communications (WiMob), Barcelona, 8-10 October 2012, 579-585.

[30] Tao, F., Zuo, Y., Da Xu, L., Lv, L. and Zhang, L. (2014) Internet of Things and BOM-Based Life Cycle Assessment of Energy-Saving and Emission-Reduction of Products. IEEE Transactions on Industrial Informatics, 10, 1252-1261. https://doi.org/10.1109/TII.2014.2306771

[31] Wei, M., Hong, S.H. and Alam, M. (2016) An IoT-Based Energy-Management Platform for Industrial Facilities. Applied Energy, 164, 607-619. https://doi.org/10.1016/j.apenergy.2015.11.107

[32] Akkaya, K., Guvenc, I., Aygun, R., Pala, N. and Kadri, A. (2015) IoT-Based Occupancy Monitoring Techniques for Energy-Efficient Smart Buildings. Wireless Communications and Networking Conference Workshops (WCNCW), New Orleans, LA, 9-12 March 2015, 58-63. https://doi.org/10.1109/WCNCW.2015.7122529

[33] De Paola, A., Ortolani, M., Lo Re, G., Anastasi, G. and Das, S.K. (2014) Intelligent Management Systems for Energy Efficiency in Buildings: A Survey. ACM Computing Surveys (CSUR), 47, Article No. 13. https://doi.org/10.1145/2611779

[34] Paya-Vaya, G. and Blume, H. (2017) Towards a Common Software/Hardware Methodology for Future Advanced Driver Assistance Systems. River Publishers, Aalborg.

[35] Byun, J., Hong, I., Lee, B. and Park, S. (2013) Intelligent Household LED Lighting System Considering Energy Efficiency and User Satisfaction. IEEE Transactions on Consumer Electronics, 59, 70-76. https://doi.org/10.1109/TCE.2013.6490243

[36] Shaikh, P.H., Nor, N.B.M., Nallagownden, P., Elamvazuthi, I. and Ibrahim, T. (2014) A Review on Optimized Control Systems for Building Energy and Comfort Management of Smart Sustainable Buildings. Renewable and Sustainable Energy Reviews, 34, 409-429. https://doi.org/10.1016/j.rser.2014.03.027

[37] General Data Protection Regulation (GDPR) (2017) General Data Protection Regulation (GDPR) -Final Text Neatly Arranged. https://gdpr-info.eu/

[38] Nguyen, T.A. and Aiello, M. (2013) Energy Intelligent Buildings Based on User Activity: A Survey. Energy and Buildings, 56, 244-257. https://doi.org/10.1016/j.enbuild.2012.09.005

[39] Ozturk, Y., Senthilkumar, D., Kumar, S. and Lee, G. (2013) An Intelligent Home Energy Management System to Improve Demand Response. IEEE Transactions on Smart Grid, 4, 694-701. https://doi.org/10.1109/TSG.2012.2235088

[40] Yang, R. and Wang, L. (2013) Development of Multi-Agent System for Building Energy and Comfort Management Based on Occupant Behaviors. Energy and Buildings, 56, 1-7. https://doi.org/10.1016/j.enbuild.2012.10.025

[41] Sarigiannidis, P., Aproikidis, K., Louta, M., Angelidis, P. and Lagkas, T. (2014) Predicting Multimedia Traffic in Wireless Networks: A Performance Evaluation of Cognitive Techniques. The 5th International Conference on Information, Intelligence, Systems and Applications, Chania, 7-9 July 2014, 341-346.

[42] Chronopoulos, S.K., Tatsis, G., Raptis, V. and Kostarakis, P. (2012) A Parallel Turbo Encoder-Decoder Scheme. Proceedings of the 2 nd Pan-Hellenic Conference on Electronics and Telecommunications, Thessaloniki, 16-18 March 2012.

[43] Chronopoulos, S.K., Tatsis, G. and Kostarakis, P. (2011) Turbo Codes-A New 
PCCC Design. Communications and Network, 3, 229-234.

https://doi.org/10.4236/cn.2011.34027

[44] Chronopoulos, S.K., Tatsis, G. and Kostarakis, P. (2012) Turbo Coded OFDM with Large Number of Subcarriers. Journal of Signal and Information Processing, 3, 161-168. https://doi.org/10.4236/jsip.2012.32021

[45] Ahmed, M.S., Mohamed, A., Khatib, T., Shareef, H., Homod, R.Z. and Ali, J.A. (2017) Real Time Optimal Schedule Controller for Home Energy Management System Using New Binary Backtracking Search Algorithm. Energy and Buildings, 138, 215-227. https://doi.org/10.1016/j.enbuild.2016.12.052

[46] Chatzoglou, P.D., Fragidis, L.L., Doumpa, T. and Aggelidis, P. (2012) Hospital Information System Evaluation. 10th International Conference on ICT in Health, Samos Island Greece, 12-14 July 2012, 240-257.

[47] Hosenuzzaman, M., Rahim, N.A., Selvaraj, J., Hasanuzzaman, M., Malek, A.B.M.A. and Nahar, A. (2015) Global Prospects, Progress, Policies, and Environmental Impact of Solar Photovoltaic Power Generation. Renewable and Sustainable Energy Reviews, 41, 284-297. https://doi.org/10.1016/j.rser.2014.08.046

[48] Sinha, S. and Chandel, S.S. (2015) Review of Recent Trends in Optimization Techniques for Solar Photovoltaic-Wind Based Hybrid Energy Systems. Renewable and Sustainable Energy Reviews, 50, 755-769. https://doi.org/10.1016/j.rser.2015.05.040

[49] Tian, Y. and Zhao, C.Y. (2013) A Review of Solar Collectors and Thermal Energy Storage in Solar Thermal Applications. Applied Energy, 104, 538-553. https://doi.org/10.1016/j.apenergy.2012.11.051

[50] Jin, H., Qin, L., Hao, C., Wang, L. and Jiao, F. (2011) The Study and Exploration of a New Generation of Photovoltaic Energy Storage System. Energy Procedia, 12, 986-993. https://doi.org/10.1016/j.egypro.2011.10.129

[51] Cheng, F., Wen, R., Huang, Z., Fang, M., Liu, Y.G., Wu, X. and Min, X. (2017) Preparation and Analysis of Lightweight Wall Material with Expanded Graphite (EG)/Paraffin Composites for Solar Energy Storage. Applied Thermal Engineering, 120, 107-114. https://doi.org/10.1016/j.applthermaleng.2017.03.129

[52] (2017) Download SmartDraw-Free Trial Software. Smartdraw.com. https://www.smartdraw.com/downloads/download.htm

[53] Aman, S., Simmhan, Y. and Prasanna, V.K. (2013) Energy Management Systems: State of the Art and Emerging Trends. IEEE Communications Magazine, 51, 114-119. https://doi.org/10.1109/MCOM.2013.6400447

[54] Kazmi, A.H., O’grady, M.J., Delaney, D.T., Ruzzelli, A.G. and O’hare, G.M. (2014) A Review of Wireless-Sensor-Network-Enabled Building Energy Management Systems. ACM Transactions on Sensor Networks (TOSN), 10, Article No. 66. https://doi.org/10.1145/2532644

[55] Magno, M., Polonelli, T., Benini, L. and Popovici, E. (2015) A Low Cost, Highly Scalable Wireless Sensor Network Solution to Achieve Smart LED Light Control for Green Buildings. IEEE Sensors Journal, 15, 2963-2973. https://doi.org/10.1109/JSEN.2014.2383996

[56] Prabhu, B., Balakumar, N. and Antony, A.J. (2017) Wireless Sensor Network Based Smart Environment Applications. IJIRT, 3, 1-10. https://ssrn.com/abstract=2909105

[57] Sarigiannidis, P.G., Pechlivanidou, V.D., Louta, M.D. and Angelidis, P. (2011) Towards an Effective Energy Efficient Passive Optical Network. 2011 IEEE Symposium on Computers and Communications (ISCC), Kerkyra, 28 June-1 July 2011, 391-396. https://doi.org/10.1109/ISCC.2011.5983869 
[58] Chavali, P., Yang, P. and Nehorai, A. (2014) A Distributed Algorithm of Appliance Scheduling for Home Energy Management System. IEEE Transactions on Smart Grid, 5, 282-290. https://doi.org/10.1109/TSG.2013.2291003

[59] Chen, C., Wang, J. and Kishore, S. (2014) A Distributed Direct Load Control Approach for Large-Scale Residential Demand Response. IEEE Transactions on Power Systems, 29, 2219-2228. https://doi.org/10.1109/TPWRS.2014.2307474

[60] Jeong, J., Hong, T., Ji, C., Kim, J., Lee, M., Jeong, K. and Koo, C. (2017) Development of a Prediction Model for the Cost Saving Potentials in Implementing the Building Energy Efficiency Rating Certification. Applied Energy, 189, 257-270. https://doi.org/10.1016/j.apenergy.2016.12.024

[61] Corke, P., Wark, T., Jurdak, R., Hu, W., Valencia, P. and Moore, D. (2010) Environmental Wireless Sensor Networks. Proceedings of the IEEE, 98, 1903-1917. https://doi.org/10.1109/JPROC.2010.2068530

[62] Feng, W., Zou, L., Gao, G., Wu, G., Shen, J. and Li, W. (2016) Gasochromic Smart Window: Optical and Thermal Properties, Energy Simulation and Feasibility Analysis. Solar Energy Materials and Solar Cells, 144, 316-323. https://doi.org/10.1016/j.solmat.2015.09.029

[63] Granqvist, C.G. (2014) Electrochromics for Smart Windows: Oxide-Based Thin Films and Devices. Thin Solid Films, 564, 1-38. https://doi.org/10.1016/j.tsf.2014.02.002

[64] Hee, W.J., Alghoul, M.A., Bakhtyar, B., Elayeb, O., Shameri, M.A., Alrubaih, M.S. and Sopian, K. (2015) The Role of Window Glazing on Daylighting and Energy Saving in Buildings. Renewable and Sustainable Energy Reviews, 42, 323-343. https://doi.org/10.1016/j.rser.2014.09.020

[65] Sarbu, I. and Sebarchievici, C. (2014) General Review of Ground-Source Heat Pump Systems for Heating and Cooling of Buildings. Energy and Buildings, 70, 441-454. https://doi.org/10.1016/j.enbuild.2013.11.068

[66] Cho, H., Smith, A.D. and Mago, P. (2014) Combined Cooling, Heating and Power: A Review of Performance Improvement and Optimization. Applied Energy, 136, 168-185. https://doi.org/10.1016/j.apenergy.2014.08.107

[67] Nastasi, B. and Basso, G.L. (2016) Hydrogen to Link Heat and Electricity in the Transition towards Future Smart Energy Systems. Energy, 110, 5-22. https://doi.org/10.1016/j.energy.2016.03.097

[68] Papantoniou, S., Kolokotsa, D. and Kalaitzakis, K. (2015) Building Optimization and Control Algorithms Implemented in Existing BEMS Using a Web Based Energy Management and Control System. Energy and Buildings, 98, 45-55. https://doi.org/10.1016/j.enbuild.2014.10.083

[69] Shaikh, P.H., Nor, N.B.M., Nallagownden, P., Elamvazuthi, I. and Ibrahim, T. (2016) Intelligent Multi-Objective Control and Management for Smart Energy Efficient Buildings. International Journal of Electrical Power \& Energy Systems, 74, 403-409. https://doi.org/10.1016/j.ijepes.2015.08.006

[70] (2017) USGBC Homepage | USGBC. New.usgbc.org. https://new.usgbc.org/

[71] Cassidy, R. (2003) White Paper on Sustainability. Building Design and Construction.

[72] Skov, P., Valbjørn, O. and Pedersen, B.V. (1990) Influence of Indoor Climate on the Sick Building Syndrome in an Office Environment. Scandinavian Journal of Work, Environment \& Health, 16, 363-371. https://doi.org/10.5271/sjweh.1772

[73] Hoskins, J.A. (2003) Health Effects Due to Indoor Air Pollution. Indoor and Built Environment, 12, 427-433. https://doi.org/10.1177/1420326X03037109 
[74] Tafiadis, D., Chronopoulos, S.K., Siafaka, V., Drosos, K., Kosma, E.I., Toki, E.I. and Ziavra, N. (2017) Comparison of Voice Handicap Index Scores between Female Students of Speech Therapy and Other Health Professions. Journal of Voice, 31, 583-588. https://doi.org/10.1016/j.jvoice.2017.01.013

[75] Tafiadis, D., Kosma, E.I., Chronopoulos, S.K., Papadopoulos, A., Drosos, K., Siafaka, V., Toki, E.I. and Ziavra, N. (2017) Voice Handicap Index and Interpretation of the Cutoff Points Using Receiver Operating Characteristic Curve as Screening for Young Adult Female Smokers. Journal of Voice, in press. https://doi.org/10.1016/j.jvoice.2017.03.009

[76] Tafiadis, D., Chronopoulos, S.K., Kosma, E.I., Voniati, L., Raptis, V., Siafaka, V. and Ziavra, N. (2017) Using Receiver Operating Characteristic Curve to Define the Cutoff Points of Voice Handicap Index Applied to Young Adult Male Smokers. Journal of Voice, in press. https://doi.org/10.1016/j.jvoice.2017.06.007

[77] Newsham, G., Brand, J., Donnelly, C., Veitch, J., Aries, M. and Charles, K. (2009) Linking Indoor Environment Conditions to Job Satisfaction: A Field Study. Building Research \& Information, 37, 129-147. https://doi.org/10.1080/09613210802710298

[78] Wargocki, P., Wyon, D.P. and Fanger, P.O. (2000) Productivity Is Affected by the Air Quality in Offices. Proceedings of Healthy Buildings, 1, 635-40.

[79] Ries, R., Bilec, M.M., Gokhan, N.M. and Needy, K.L. (2006) The Economic Benefits of Green Buildings: A Comprehensive Case Study. The Engineering Economist, 51, 259-295. https://doi.org/10.1080/00137910600865469

[80] Fowler, K.M., Dyer, B., Berlow, C., Glover, S., Howell, C., Talton, D. Todd, J. and Walker, A. (2004) Building Cost and Performance Measurement Data. Green-Build 2004 International Conference and Expo, Portland, OR, 10-12 November 2004.

[81] U.S. Green Building Council (2009) Regional Green Building Case Study Project: A Post-Occupancy Study of LEED Projects in Illinois. Center for Neighborhood Technology. https://www.cnt.org/sites/default/files/publications/CNT_Exec-Summary-RegionalGreen-Building-Case-Study-Project-Year-1-Report.pdf

[82] Heerwagen, J. (2000) Green Buildings, Organizational Success and Occupant Productivity. Building Research \& Information, 28, 353-367. https://doi.org/10.1080/096132100418500

[83] Kaplan, S. (1995) The Restorative Benefits of Nature: Toward an Integrative Framework. Journal of Environmental Psychology, 15, 169-182.

https://doi.org/10.1016/0272-4944(95)90001-2

[84] Heerwagen, J. and Zagreus, L. (2005) The Human Factors of Sustainable Building Design: Post Occupancy Evaluation of the Philip Merrill Environmental Center. https://escholarship.org/uc/item/67j1418w

[85] Heerwagen, J.H., Kampschroer, K., Powell, K.M. and Loftness, V. (2004) Collaborative Knowledge Work Environments. Building Research \& Information, 32, 510-528. https://doi.org/10.1080/09613210412331313025

[86] Gutwin, C. and Greenberg, S. (2002) A Descriptive Framework of Workspace Awareness for Real-Time Groupware. Computer Supported Cooperative Work (CSCW), 11, 411-446. https://doi.org/10.1023/A:1021271517844

[87] Heerwagen, J., Loveland, J. and Diamond, R. (1991) Post Occupancy Evaluation of Energy Edge Buildings. University of Washington. Center for Planning and Design.

[88] Zijlstra, F.R., Roe, R.A., Leonora, A.B. and Krediet, I. (1999) Temporal Factors in Mental Work: Effects of Interrupted Activities. Journal of Occupational and Orga- 
nizational Psychology, 72, 163-185. https://doi.org/10.1348/096317999166581

[89] Lee, Y.S. and Guerin, D.A. (2009) Indoor Environmental Quality Related to Occupant Satisfaction and Performance in LEED-Certified Buildings. Indoor and Built Environment, 18, 293-300. https://doi.org/10.1177/1420326X09105455

[90] Sundell, J. (2004) On the History of Indoor Air Quality and Health. Indoor Air, 14, 51-58. https://doi.org/10.1111/j.1600-0668.2004.00273.x

[91] Wargocki, P., Wyon, D.P., Baik, Y.K., Clausen, G. and Fanger, P.O. (1999) Perceived Air Quality, Sick Building Syndrome (SBS) Symptoms and Productivity in an Office with Two Different Pollution Loads. Indoor Air, 9, 165-179.

https://doi.org/10.1111/j.1600-0668.1999.t01-1-00003.x

[92] Allen, J.G., MacNaughton, P., Satish, U., Santanam, S., Vallarino, J. and Spengler, J.D. (2016) Associations of Cognitive Function Scores with Carbon Dioxide, Ventilation, and Volatile Organic Compound Exposures in Office Workers: A Controlled Exposure Study of Green and Conventional Office Environments. Environmental health perspectives, 124,805 .

[93] MacNaughton, P., Spengler, J., Vallarino, J., Santanam, S., Satish, U. and Allen, J. (2016) Environmental Perceptions and Health before and after Relocation to a Green Building. Building and Environment, 104, 138-144. https://doi.org/10.1016/j.buildenv.2016.05.011

[94] Allen, J.G., MacNaughton, P., Laurent, J.G.C., Flanigan, S.S., Eitland, E.S. and Spengler, J.D. (2015) Green Buildings and Health. Current Environmental Health Reports, 2, 250-258. https://doi.org/10.1007/s40572-015-0063-y

[95] Thatcher, A. and Milner, K. (2014) Changes in Productivity, Psychological Wellbeing and Physical Wellbeing from Working in a "Green" Building. Work, 49, 381-393.

[96] Singh, A., Syal, M., Grady, S.C. and Korkmaz, S. (2010) Effects of Green Buildings on Employee Health and Productivity. American Journal of Public Health, 100, 1665-1668. https://doi.org/10.2105/AJPH.2009.180687

[97] Hedge, A. and Dorsey, J.A. (2013) Green Buildings Need Good Ergonomics. Ergonomics, 56, 492-506. https://doi.org/10.1080/00140139.2012.718367

[98] Hedge, A., Miller, L. and Dorsey, J.A. (2014) Occupant Comfort and Health in Green and Conventional University Buildings. Work, 49, 363-372.

[99] Vantablack| Surrey NanoSystems (2017) Surreynanosystems.com. https://www.surreynanosystems.com/vantablack 


\section{Abbreviations List}

$$
\begin{aligned}
& \text { AMI = Advanced Metering Infrastructure } \\
& \text { ASA = Advanced Sensor Applications } \\
& \text { BRI = Building Related Illness } \\
& \text { CHSC = Common Harmonized Software Control } \\
& \text { GDPR = General Data Protection Regulation } \\
& \text { HESS = Home Energy Storage System } \\
& \text { IAQ = Indoor Air Quality } \\
& \text { IEQ = Indoor Environmental Quality } \\
& \text { IoT = Internet of Things } \\
& \text { LEED = Leadership in Energy and Environmental Design } \\
& \text { MCS = Multiple Chemical Sensitivity } \\
& \text { PAR = Peak-to-Average Ratio } \\
& \text { REFF = Reduced Ecological Footprints of Facilities } \\
& \text { SBS = Sick Building Syndrome }
\end{aligned}
$$

